\title{
Linkage of the tuberous sclerosis locus to a polymorphism detected by $\mathrm{v}-\mathrm{abl}$
}

\author{
J M CONNOR, L A PIRRIT, J R W YATES, A E FRYER*, AND
} M A FERGUSON-SMITH

From the Duncan Guthrie Institute of Medical Genetics, Yorkhill, Glasgow G3 8SJ; and ${ }^{*}$ Royal United ${ }^{\infty}$ Hospital, Bath.

SUMMARY Linkage analysis was undertaken in six families with tuberous sclerosis (TS) using restriction fragment length polymorphism detected by v-abl. No recombinants were observed im 13 informative meioses (four phase known) giving a maximum lod score of 3.18 at zeró recombination (confidence limits 0 to $0 \cdot 15$ ). This provides further evidence for the assignment of TS to $9 q 34$ and should facilitate cloning of the structural gene, genetic counselling, and first芦 trimester prenatal diagnosis.

Tuberous sclerosis (TS) is an autosomal dominant disorder with a variable phenotype which commonly includes hypopigmented skin macules, adenoma sebaceum, ungual fibromas, seizures, and mental retardation. ${ }^{1}$ The initial suggestion of linkage of TS to the ABO blood group ${ }^{2}$ has recently been confirmed in a collaborative UK study. ${ }^{3}$ This maps the locus for TS to $9 \mathrm{q} 34$. We provide here further evidence for this assignment.

\section{Methods}

Six families with TS suitable for linkage analysis

Received for publication 16 April 1987. Accepted for publication 30 April 1987. were ascertained from the genetic records of theD West of Scotland Regional Genetics Centre. Alচ affected subjects conformed to the diagnostic criteria of Gomez ${ }^{1}$ and unaffected subjects at risk were rigorously investigated as detailed elsewhere. ${ }^{3} \cdot \vec{c}$

The methods for DNA extraction and restriction fragment identification have been describs previously. ${ }^{4}$ DNA from each family member digested with TaqI and after electrophoresis ands Southern blotting was probed with pSA-19 which iso a $1.9 \mathrm{~kb}$ fragment of $\mathrm{v}-a b l .^{5}$ Lod scores wereo calculated using the computer programme LIPED $\stackrel{{ }^{\circ}}{2}$ assuming a penetrance of $98 \%$ and the confidences interval was determined by taking values of the 3 recombination fraction corresponding to a lod score? one unit less than the maximum. ${ }^{8}$
GLA

4136

I

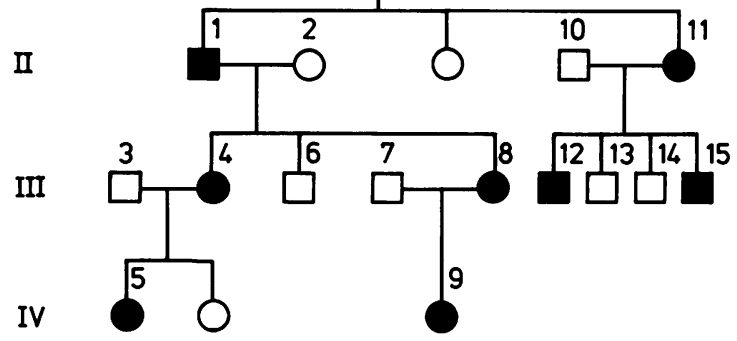

GLA

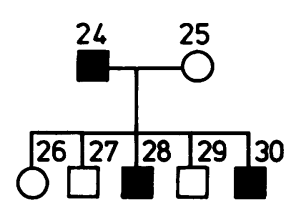

GLA

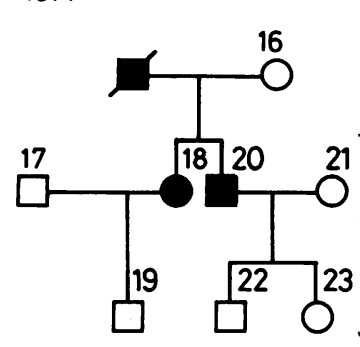

FIG 1 Abbreviated pedigrees of informative TS families. Numbers above symbols correspond to lanes in fig 2. 

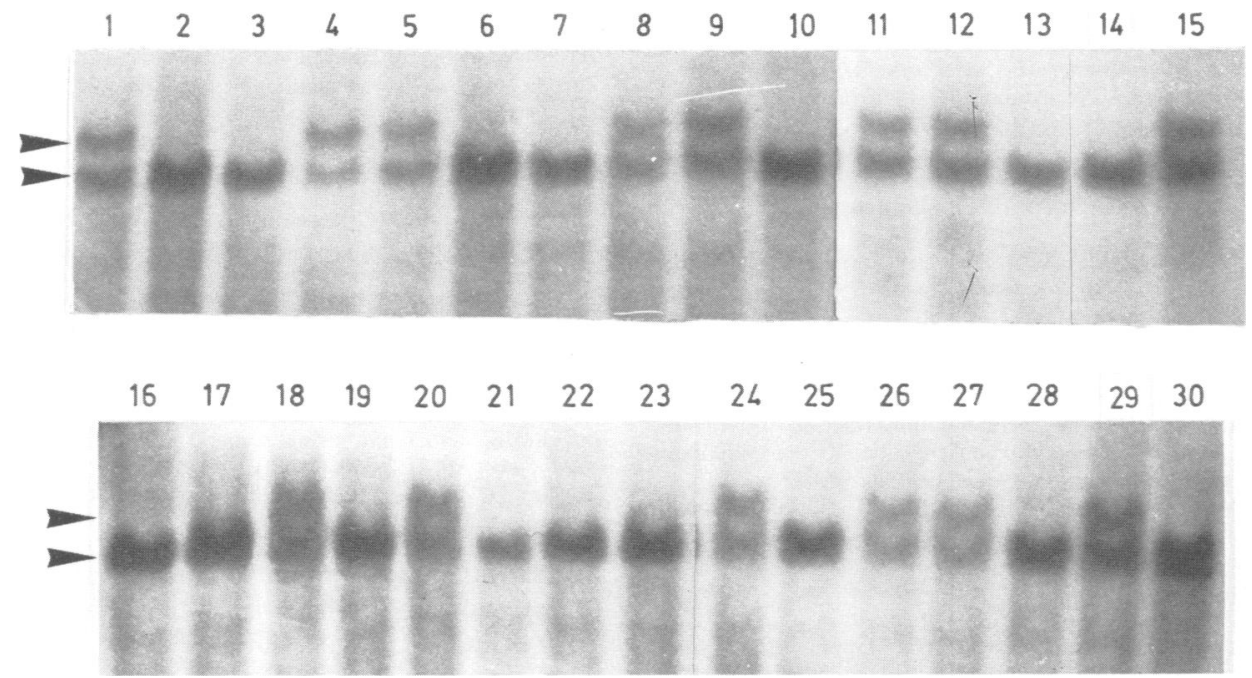

FIG 2 TaqI digested DNA probed with v-abl (pSA-19). Polymorphic bands are arrowed and lane numbers correspond to the subjects shown in fig 1 .

\section{Results}

Three of the six families were informative for this RFLP and their pedigrees and DNA autoradiographs are shown in figs 1 and 2 . Subjects $6,13,14$, 27 , and 29 had normal clinical and ophthalmological examinations (including examination of the skin under ultraviolet light) but were excluded from the analysis because they had not had cranial CT scans, renal ultrasound, and $x$ rays of the hands and feet, as demanded by the rigorous protocol adopted for an earlier study. ${ }^{3}$ With these exclusions no recombinations were observed in 13 informative meioses giving a peak lod score of $3 \cdot 18$ at zero recombination (table). If these subjects had been included as unaffected there would have been no recombinations in 18 informative meioses giving a maximum lod score of 4.64 at zero recombination.

\section{Discussion}

The human oncogene c-abl is the cellular homo-

TABIE Lod scores at different values of the recombination fraction $(\theta)$ for tuberous sclerosis versus $v$-abl.

\begin{tabular}{lllllllll}
\hline Recombination fraction $(\theta)$ \\
\hline 0 & 0.05 & 0.1 & 0.2 & 0.3 & 0.4 & $\hat{Z}$ & $\dot{\theta}$ & $\begin{array}{l}\text { Confidence } \\
\text { limit for } \theta\end{array}$ \\
\hline 3.18 & 2.85 & 2.52 & 1.83 & 1.13 & 0.47 & 3.18 & 0 & $0-0.15$ \\
\hline
\end{tabular}

$\hat{\mathrm{Z}}=$ maximum lod score, $\hat{\boldsymbol{\theta}}=$ corresponding value of recombination fraction. logue of the transforming sequence v- $a b l$ which was first discovered in the Abelson strain of murine leukaemia virus (A-MuLV). The coding sequences for $\mathrm{c}-a b l$ extend over a 225 to $300 \mathrm{~kb}$ region and the $\mathrm{v}-a b l$ homologous regions (VAHR) are located at its $3^{\prime}$ end. ${ }^{9}$ Human $c-a b l$ has been localised to $9 \mathrm{q} 34$ by in situ hybridisation and somatic cell hybrid panels and is transferred to chromosome 22 in the reciprocal translocation which creates the Philadelphia chromosome. $^{10-14}$ The adenylate kinase 1 (AK1) linkage group has also been regionally localised to $9 \mathrm{q} 34$ by dosage studies using children with various imbalances of chromosome $9,{ }^{15}$ but unlike c- $a b l$ is not transferred to chromosome 22 in the Philadelphia chromosome ${ }^{16}$ which would suggest that $\mathrm{c}-a b l$ is distal to $\mathrm{AK} 1$.

Using c-abl (ablK-2) Barker and White ${ }^{17}$ have described diallelic polymorphisms with TaqI, PstI, $A c c I$, and StuI (each with an infrequent allele frequency of $0 \cdot 11$ ). The present study using the Taq I polymorphism detected by $\mathrm{v}-a b l$ has shown linkage to TS and provides further evidence for the assignment of TS to $9 \mathrm{q} 34$. This marker will be more useful for early prenatal diagnosis than the $\mathrm{ABO}$ or $\mathrm{AK} 1$ loci and will aid attempts to clone the structural gene for TS.

We wish to thank the Wellcome Trust (JMC), the Scottish Hospital Endowments Research Trust (JMC), the Tuberous Sclerosis Association of Great Britain (AEF), Cow and Gate Ltd (AEF), and the Bath Unit for Research into Paediatrics (AEF) for financial support. 


\section{References}

1 Gomez MR. Tuberous sclerosis. New York: Raven Press, 1979.

- Connor JM, Yates JRW, Mann L, Aitken DA. Stephenson JBP. Tuberous sclerosis: analysis of linkage to red cell and plasma protein markers. Cytogenet Cell Genet 1987:44:63-4.

3 Fryer AE, Chalmers A, Connor JM, et al. Evidence that the gene for tuberous sclerosis is on chromosome 9. Lancet 1987;i:659-61.

+ Connor JM, Gatherer D, Gray FC, et al. Assignment of the gene for dyskeratosis congenita to $\mathrm{Xq} 28$. Hum Genet 1986;72:348-51.

5 Dale B, Ozanne B. Characterization of mouse cellular decxyribonucleic acid homologous to Abelson murine leukaemia virus-specific sequences. Mol Cell Biol 1981;1:731-42.

6 Ott $\mathbf{J}$. Estimation of the recombination fraction in human pedigrees: efficient computation of the likelihood for human linkage studies. Am J Hum Genet 1974;26:588-97.

7 Connor JM, Stephenson JBP, Hadley MDM. Non-penetrance in tuberous sclerosis. Lancet 1986;ii: 1275.

* Conneally PM, Edwards JH, Kidd KK, et al. Report of the committee on methods of linkage analysis and reporting. HGM8. Cytogenet Cell Genet 1985;40:356-9.

"Rubin CM, Westbrook CA. Rowley JD. Mapping of the c-abl locus using pulsed field electrophoresis: application to the analysis of chromosome translocations. Am J Hum Genet 1986;399:40A.

11 Heisterkamp N, Groffen J, Stephenson JR, et al. Chromosomal localization of human cellular homologues of two viral oncogenes. Nature 1982;299:747-9.

"De Klcin A, Geurts van Kessel A. Grosveld G, et al. A cellular oncogene is translocated to the Philadelphia chromosome in chronic myelocytic leukacmia. Nature 1982;300:765-7.
12 Heisterkamp N, Stephenson JR, Groffen J, et al. Localization of the c-abl oncogene adjacent to a translocation break point in $\stackrel{\mathbb{P}}{?}$ chronic myelocytic leukaemia. Nature 1983;306:239-42.

13 Bartram CR, de Klein A, Hagemeijer A, et al. Translocation o $\overrightarrow{\overline{5}}$ $\mathrm{c}-a b l$ oncogene correlates with the presence of a Philadelphia chromosome in chronic myelocytic leukaemia. Naturec 1983;306:277-80.

14 Jhanwar SC, Neel BG, Hayward WS, Chaganti RSK. Localisa $\frac{\overline{\bar{S}}}{7}$ tion of the cellular oncogenes ABL, SIS and FES on humand germ line chromosomes. Cytogenet Cell Genet 1984;38:73-5으

15 Ferguson-Smith MA, Aitken DA, Turleau C, de Grouchy J Localisation of the human ABO:NP-1:AK1 linkage group by regional assignment of $A K 1$ to $9 q 34$. Hum Genet 1976;34:35-43.

16 Geurts van Kessel AHM, Hagemeijer A, Westerveld A, et al.Characterization of chromosomal abnormalities in chronicu myclocytic leukaemia using somatic cell hybrids. Cytogene? Cell Genet 1982;32:280.

17 Barker D, White R. DNA polymorphisms at oncogene lock Cytogenet Cell Genet 1984;37:228.

Correspondence and requests for reprints to Dr J M Connor, Duncan Guthrie Institute of Medical Gene $\stackrel{+}{+}$ tics, Yorkhill, Glasgow G3 8SJ.

\section{Note added in proof}

Since submission, first trimester prenatal exclusion has been performed using this RFLP for subject 12 in GLA 4136 and his wife. 